\title{
Nurses' Knowledge and Performance regarding Care for Children with Poisoning at Emergency Unit
}

\author{
Amal Abdrbou Hussien, Saleh Eldien Emery, Shokria Adely Labeeb, \& Salwa Ali Marzouk. \\ Assistant Lecture of Pediatric Nursing, Faculty of Nursing, Assiut University, Egypt \\ Professor of Pediatric, Faculty of medicine, Assuit university, Egypt \\ Professor of Community Health Nursing, Faculty of Nursing, Assuit University Egypt \\ Assistant professor of Pediatric Nursing Department, Faculty of Nursing, Assiut University, Egypt
}

\begin{abstract}
:
Poisoning of children is one of the most common and important subject in the field of pediatric nursing. Many children are admitted to hospital because they have been poisoned by eating, drinking, or even inhaling poisonous substances. There are several unique aspects in the clinical assessment and management of childhood poisoning that need to be considered. So, the aims of this study were to assess the nurses' knowledge and practice about care given to the child with poisoning. A descriptive study design was carried out. The subjects included 30 nurses working in emergency unit of Assuit University Children Hospital. Data collection tools were a structured questionnaire interview sheet and an observation checklist. In conclusion, the study revealed deficiency in knowledge and practices. Statistically significant relations were shown between knowledge and practices among studied nurses. The study recommended developed program should be applied for nurses about care given to the child with poisoning.
\end{abstract}

Key Words: Poisoning, Nurses, knowledge and practice

\section{Introduction:}

Poisoning is still an important issue in Egypt; Childhood poisoning is a major cause of morbidity in the developing as well as the developed countries. Unintentional poisoning may occur as part of cognitive development in young children. Poisoning of children is one of the most common and important subject in the field of pediatric nursing, a poison is a substance which introduced into the body injures or destroys the tissues and enzymes. It can cause a serious threat to life, depending on the amount, type and concentration of the poisonous substance and also the immediate nursing intervention (Sandra, 2010).

The most common causes of poisoning in young children are: drugs, medicines, cleaning products, plants, make-up, pesticides, paints and solvents. Medicines that contain iron (like many multivitamins) are one of the most common causes of poisoning in children under age 5 years (Spady, 2004).

Poisoning can occur when a toxic substance (toxin) is swallowed (ingested) or breathed in through the mouth or nose (inhaled), gets on the skin or in the eyes, or is injected under the skin (e.g., through a bite or sting). In some cases, exposure to a very small amount of toxin can cause poisoning and in other cases, a large amount of toxin is needed (Morries, 2003).

There are different types of poisoning e.g. corrosives which include drainage liquids, toilet and oven cleaners, electric liquid dishwasher, detergents, batteries and clinitest tablets. Hydrocarbons are other types of poisoning and they include gasoline, kerosene, lamp oil, mineral seal oil, lighter fluid, turpentine and paint thinner (Lewis-Abney, 2000). Acetaminophen, aspirin, iron, plants and lead poisoning are other types of poisoning. In spite of the success of some interventions to prevent accidental poisoning in the pediatric population, toxic ingestions continue to be a common occurrence (Spady, 2004). The snake-bite and scorpion stings were two of the most common causes of injury, In Egypt specifically. The venom of these scorpions is neurotoxin, and their sting will result in death by asphyxiation. Scorpion is very hardy animals that are resistant to hunger and thirst (Wilkinson and Richard, 2003).

Management approaches of pediatric nurse was vary depending on the type of poison, the type of exposure (ingested, inhaled) the amount of exposure and the time lapse between exposure and treatment (Elesiver, 2009). The first priority is assessing the child airway, breathing, and circulation and then stabilizing the child. The four primary interventions for ingestion poisoning include the placement of a nasogastric tube for gastric lavage, administration of activated charcoal, administration of cathartic agents and administration of antidotes specific to the poison substance (Spratto and Woods, 2008).

The emergency department is primarily determined by the thorough history obtained from a parent or caregiver and observing for clinical signs indicative of poisoning. Appropriate initial decision-making in a poisoned child requires accurate identification of the substance (name, manufacturer, quantities, concentrations and production date), amount ingested 
and the time interval since ingestion (Riodan et al., 2002).

Cardiopulmonary Resuscitation (CPR) or basic life support, it is indicated in any situation in which breathing, heartbeat, or both are absent and nurses are generally the first responders to a cardiac arrest and initiate basic life support while waiting for the advanced cardiac life support team to arrive. When a child presents with suspected poisoning, begin with an assessment of the airway, breathing and circulation (Hwang et al., 2003).

The mastery of the suctioning procedure is crucial and may be life saving in emergency setting where the nurse might be confronted with a child with lifethreatening respiratory conditions. Thus, the nurse must be aware of and be able to adequately perform all steps of suctioning and additionally must document complete accurate records for suction such as time, amount required, and observation of the patient (Masoud, 2006).

\section{Significance of the study}

More than 2 million poisoning occur each year in the U.S. and more than $50 \%$ are among children 5 years old or less (Catherine and Ardys, 2009). In 2004, acute poisoning caused more than 45000 deaths in children and youth under 20 years of age $-13 \%$ of all fatal accidental poisoning worldwide. In 16 highincome and middle-income countries, poisoning is the fourth biggest cause of unintentional injury after road traffic injuries, fires and drowning. Africa and low-income and middle-income countries in Europe and the Western Pacific Regions have the highest rates (WHO, 2004).

During the researchers' work in Emergency Unit at the Assiut University Children Hospital, it has been observed that nurses were lacking the necessary basic knowledge and practices related to caring of children with poisoning. Also, the basic knowledge and nursing activities regarding poisoning can differ from health care institution to another. Therefore, special studies should be carried out to explore nurses' knowledge and identify their practices regarding poisoning in order to determine the gaps, defects and work necessary to overcome those defects. As each nurse is dealing with many children. Nurses' knowledge and practices will have great effect and will be reflected on high number of children. So, this study was designed in a trial to assess nurses' knowledge and practices regarding care offered to children with poisoning.

\section{Aim Of The Study:}

This study aimed to assess the nurses' knowledge and practice regarding care offered to the child with poisoning at emergency unit.

\section{Research questions:}

- What is the nurses' knowledge about poisoning at emergency unit?

- What is the current nursing care offered to children with poisoning?

- Is there a relationship between the studied nurses' personal characteristics and their knowledge and practices about care given to the child with poisoning?

\section{Subjects And Methods}

\section{1-Design}

A descriptive research design was utilized in the present study.

\section{2-Setting}

The study was conducted in Emergency Unit at Assuit University Children Hospital.

\section{3- Sample}

All nurses working in Emergency Unit at Assuit University Children Hospital. Total number was 30 nurses having bachelor in nursing science (3) and technical nursing diploma (27).

\section{4- Tools of data collection:-}

Two tools were utilized to collect data pertinent to the study:-

Tool I: A structured questionnaire sheet included two parts:-

Part I- Personal and socio-demographic characteristics: as age, qualification, job position, duration of nursing total and current job experience and previous attendance of training courses.

Part II- Assessment of knowledge: This part was developed by the researcher to assess the nurses' knowledge about the poisoning. It included 28 questions about definitions of poison, occurrence of poisoning, classification of poison, causes of poisoning, complication, management and prevention of poisoning.

Scoring system: for knowledge questions, each complete answer took 2 grads; incomplete (1) while wrong (0). Total grads of knowledge questions equal 115 marks. The total knowledge score was classified as:

* Poor satisfactory: < 60\%. (Less than 60 marks)

* Good satisfactory: 60\% and more. (60 marks and more)

Tool II: Observation Checklist: it was adopted from Wong, et al., (2001) and Weshus (2004) and developed by the researcher to evaluate nurses' practices given to child with poisoning. It includes the following practices:-

- Taking history (4 items)

- Vital signs (55 items)

- Suction (oral or nasal) (21 items)

- Gastric lavage (11 items)

- Resuscitation. (9 items) 
Scoring system : The items observed to be done correctly were scored " $1 "$ and the items not done correctly were scored " 0 ". The practice was considered adequate if the percent score was $60 \%$ or more and inadequate if less than $60 \%$.

\section{Methods:}

\section{Preparatory phase:}

During this phase the researcher reviewed related literature, both local and international to acquire indepth knowledge about the subject, and to be able to design the data collection forms. Then, the tools were prepared and reviewed by experts in nursing and medicine to ascertain their content validity.

- Before starting this study, it was necessary to secure the approval of authorities in the setting of the study. Therefore, an official letter was obtained from the Dean of the Faculty of Nursing to the Head of the Emergency unit, as well as the Head of Nursing Services Administration Department, soliciting the necessary approvals to conduct the research. The aim and methodology of the study was explained to administrators, and as well as potential participants.

Pilot study:

After developing the tools, a pilot study was implemented on $10 \%$ of the expected sample size in Emergency Unit at Assuit University children Hospital. A pilot study was conducted for purpose to test clarity, completeness, and to determine the time involvement. According to the results of pilot, the needed modification, omissions, and/or additions were done. A jury acceptance of the final forms was secured before actual study work and the reliability was assessed in a pilot study.

\section{Ethical consideration:}

The researcher explained to nurses the aim of the study and informed that the information obtained would be confidential and only for the purpose of the study. Nurses have ethical rights to participate or refuse participation in the study. Consent to participate in the study was written from director and oral from nurses.

\section{Field of the work:}

The field work was carried out through a period of 7 months starting from March to October. The actual work started by meeting the nurses throughout the morning shift, the researcher first introduced herself to nurses and gave them a complete background about the study and its aim, then the sheet format, pre- designed by the researcher in Arabic Language was distributed in order to collect the required data. The researcher was available for more clarification whenever needed. Observation checklist was done by the researcher herself. The researcher observed the nurses during theirs actual work to assess their practice regarding taking history, vital sign, suctioning oral or nasal, gastric lavage and resuscitation practices and each nurse observed individually. Each nurse was taken about 15-20 minute to fill the questionnaire sheet and 15-20 minute for each procedure. In the day, the researcher observed from 2-3 nurses.

Data analysis:

Data were analyzed using statistical package for social sciences (SPSS) version 20. Data were presented using descriptive statistics in the form of frequencies and quantitative data were presented by means and standard deviation, while qualitative data were presented by frequency distribution. Correlation analysis was used for assessment of inter relationship between the total score of performance, A significance level was considered at $P<0.05$.

\section{Results:}

Table (1) : Sociodemographic characteristics of the studied nurses

\begin{tabular}{|c|c|c|}
\hline Item & $(\mathbf{N}=\mathbf{3 0})$ & $\%$ \\
\hline \multicolumn{3}{|c|}{ Age:(in years) } \\
\hline$<24$ & 8 & 26.7 \\
\hline $24-28$ & 14 & 46.7 \\
\hline $29-33$ & 5 & 16.7 \\
\hline$\geq 34$ & 3 & 10.0 \\
\hline \multicolumn{3}{|c|}{ Mean \pm SD $27.19 \pm 8.77$} \\
\hline \multicolumn{3}{|c|}{ Years of experience: } \\
\hline$<5$ & 5 & 16.7 \\
\hline $5-10$ & 14 & 46.7 \\
\hline$>10$ & 11 & 36.7 \\
\hline \multicolumn{3}{|c|}{ Mean \pm SD $11.24 \pm 4.90$} \\
\hline \multicolumn{3}{|c|}{ Years of experience in current place: } \\
\hline$<5$ & 9 & 30.0 \\
\hline $5-10$ & 12 & 40.0 \\
\hline$>10$ & 9 & 30.0 \\
\hline \multicolumn{3}{|c|}{ Mean \pm SD 9.88 \pm 3.74} \\
\hline \multicolumn{3}{|c|}{ Attending training courses: } \\
\hline Yes & 18 & 60.0 \\
\hline No & 12 & 40.0 \\
\hline
\end{tabular}

Table (2) : knowledge of the studied nurses regarding poisoning

\begin{tabular}{|l|c|c|}
\hline \multirow{2}{*}{} & \multicolumn{2}{|c|}{ Incorrect } \\
\cline { 2 - 3 } & No. & $\%$ \\
\hline Definition of poison & 30 & 100 \\
\hline Definition of poisoning & 30 & 100 \\
\hline $\begin{array}{l}\text { Definition of chronic and } \\
\text { poisoning }\end{array}$ & 30 & 100 \\
\hline Classification of poisoning & 30 & 100 \\
\hline
\end{tabular}


Table (3) : knowledge of the studied nurses regarding poisoning.

\begin{tabular}{|c|c|c|c|c|}
\hline \multirow[b]{2}{*}{ Types of poisoning: } & \multicolumn{2}{|c|}{ Incomplete } & \multicolumn{2}{|c|}{ Incorrect } \\
\hline & No. & $\%$ & No. & $\%$ \\
\hline $\begin{array}{l}\text { 1) Food poisoning: } \\
\text { Signs and symptoms }\end{array}$ & 6 & 20.0 & 24 & 80 \\
\hline Treatment & 29 & 96.7 & 1 & 3.3 \\
\hline Prevention & 2 & 6.7 & 28 & 93.3 \\
\hline \multicolumn{5}{|l|}{ 2) Drug poisoning: } \\
\hline Causes & 23 & 76.7 & 7 & 23.3 \\
\hline Drug-causing poison & 11 & 36.7 & 19 & 63.3 \\
\hline Sign and symptoms & 28 & 93.3 & 2 & 6.7 \\
\hline Treatment & 25 & 83.3 & 5 & 16.7 \\
\hline Complication & 0 & 0.0 & 30 & 100 \\
\hline Prevention & 4 & 13.3 & 26 & 86.7 \\
\hline \multicolumn{5}{|l|}{ 3) Insecticides: } \\
\hline Signs and symptoms & 14 & 46.7 & 16 & 53.3 \\
\hline Treatment & 17 & 56.7 & 13 & 43.3 \\
\hline \multicolumn{5}{|l|}{ 4) Chlorine (Toxaphene) } \\
\hline Signs and symptoms & 4 & 13.3 & 26 & 86.7 \\
\hline Treatment & 0 & 0.0 & 30 & 100.0 \\
\hline \multicolumn{5}{|l|}{ 5) Pesticides Alkorad: } \\
\hline Signs and symptoms & 0 & 0.0 & 30 & 100.0 \\
\hline Treatment & 3 & 10.0 & 27 & 90.0 \\
\hline \multicolumn{5}{|l|}{ pion and snake bite: } \\
\hline Signs and symptoms & 7 & 23.3 & 23 & 76.7 \\
\hline First aid of scorpion and snake bite & 7 & 23.3 & 23 & 76.7 \\
\hline Factors that affect the severity of the bite-toxins & 2 & 6.7 & 28 & 93.3 \\
\hline \multicolumn{5}{|l|}{ 7) Kerosene: } \\
\hline Signs and symptoms & 19 & 63.3 & 11 & 36.7 \\
\hline Treatment of toxins flyer & 23 & 76.7 & 7 & 23.3 \\
\hline 8) Contraindication of gastric lavage & 24 & 80.0 & 6 & 20.0 \\
\hline
\end{tabular}

Table (4) : practice of nurses in the study sample $(n=30)$

\begin{tabular}{|c|c|c|c|c|c|c|}
\hline & \multicolumn{2}{|c|}{$\begin{array}{c}\text { Done } \\
\text { correctly }\end{array}$} & \multicolumn{2}{|c|}{$\begin{array}{c}\text { Done } \\
\text { incorrectly }\end{array}$} & \multicolumn{2}{|c|}{ Not done } \\
\hline & No. & $\%$ & No. & $\%$ & No. & $\%$ \\
\hline $\begin{array}{l}\text { 1-Taking history: } \\
\text { 1- Obtain socio-demographic data name, age and sex of the child } \\
\text { 2-information related to poisons }\end{array}$ & $\begin{array}{l}5 \\
0\end{array}$ & $\begin{array}{c}16.7 \\
0\end{array}$ & $\begin{array}{l}9 \\
4\end{array}$ & $\begin{array}{c}30 \\
13.3\end{array}$ & $\begin{array}{l}16 \\
26\end{array}$ & $\begin{array}{l}53.3 \\
86.7\end{array}$ \\
\hline 3-Taking anthropometric measurement & 8 & 26.7 & 4 & 13.3 & 18 & 60.0 \\
\hline
\end{tabular}


Table (5): Nurses' practice offered to poising children in the studied sample.

\begin{tabular}{|l|c|c|c|c|}
\hline \multirow{2}{*}{ Practices } & \multicolumn{2}{c|}{ Adequate } & \multicolumn{2}{c|}{ Inadequate } \\
\cline { 2 - 5 } & No. & $\%$ & \multicolumn{2}{c|}{ No. } \\
\hline Vital sign: & \multicolumn{3}{|c|}{$\%$} \\
\hline Temperature & 28 & 93.3 & 2 & 90 \\
\hline Apical pulse & 3 & 10 & 27 & 90 \\
\hline Respiration & 3 & 10 & 27 & 76.7 \\
\hline Blood pressure & 7 & 23.3 & 23 & 93.3 \\
\hline Suctioning & 2 & 6.7 & 28 & 83.4 \\
\hline CPR & 5 & 16.6 & 25 & 60 \\
\hline Gastric lavage & 12 & 40 & 18 & 6 \\
\hline
\end{tabular}

Table (6) : Relationship between nurses' knowledge and practice and their socio-demographic characteristics.

\begin{tabular}{|c|c|c|c|c|}
\hline \multirow[t]{2}{*}{ Item } & \multicolumn{2}{|c|}{ Knowledge } & \multicolumn{2}{|c|}{ Practice } \\
\hline & Mean \pm SD & Range & Mean \pm SD & Range \\
\hline $\begin{array}{l}\text { Age in years: } \\
\leq 28 \\
>28 \\
\end{array}$ & $\begin{array}{l}10.23 \pm 2.74 \\
11.00 \pm 2.45 \\
\end{array}$ & $\begin{array}{l}5-16 \\
6-14\end{array}$ & $\begin{array}{l}47.00 \pm 28.07 \\
41.38 \pm 23.70\end{array}$ & $\begin{array}{l}0-152 \\
16-73\end{array}$ \\
\hline P-value & \multicolumn{2}{|c|}{0.489} & \multicolumn{2}{|c|}{0.618} \\
\hline $\begin{array}{l}\text { Years of experience: } \\
<5 \\
5-10 \\
>10\end{array}$ & $\begin{array}{c}9.60 \pm 2.70 \\
10.64 \pm 2.95 \\
10.55 \pm 2.38\end{array}$ & $\begin{array}{l}7-14 \\
5-16 \\
6-14 \\
\end{array}$ & $\begin{array}{l}34.20 \pm 19.65 \\
49.43 \pm 32.46 \\
45.64 \pm 21.37\end{array}$ & $\begin{array}{c}0-50 \\
19-152 \\
16-73\end{array}$ \\
\hline$P$-value & \multicolumn{2}{|c|}{0.753} & \multicolumn{2}{|c|}{0.565} \\
\hline \multicolumn{5}{|c|}{ Working in other place: } \\
\hline $\begin{array}{l}\text { Yes } \\
\text { No }\end{array}$ & $\begin{array}{l}10.00 \pm 2.96 \\
10.62 \pm 2.56\end{array}$ & $\begin{array}{l}5-13 \\
6-16 \\
\end{array}$ & $\begin{array}{l}39.78 \pm 14.16 \\
47.95 \pm 30.53\end{array}$ & $\begin{array}{l}19-67 \\
0-152 \\
\end{array}$ \\
\hline$P$-value & \multicolumn{2}{|c|}{0.567} & \multicolumn{2}{|c|}{0.452} \\
\hline \multicolumn{5}{|c|}{ Attending training courses: } \\
\hline $\begin{array}{l}\text { Yes } \\
\text { No }\end{array}$ & $\begin{array}{l}10.33 \pm 2.93 \\
10.58 \pm 2.28\end{array}$ & $\begin{array}{l}5-16 \\
7-14\end{array}$ & $\begin{array}{l}10.33- \pm 2.93 \\
10.58 \pm-2.28\end{array}$ & $\begin{array}{l}5-16 \\
7-14\end{array}$ \\
\hline$P$-value & \multicolumn{2}{|c|}{0.805} & \multicolumn{2}{|c|}{0.805} \\
\hline
\end{tabular}

Figure (1): Distribution of the children according to the type of their poisoning.

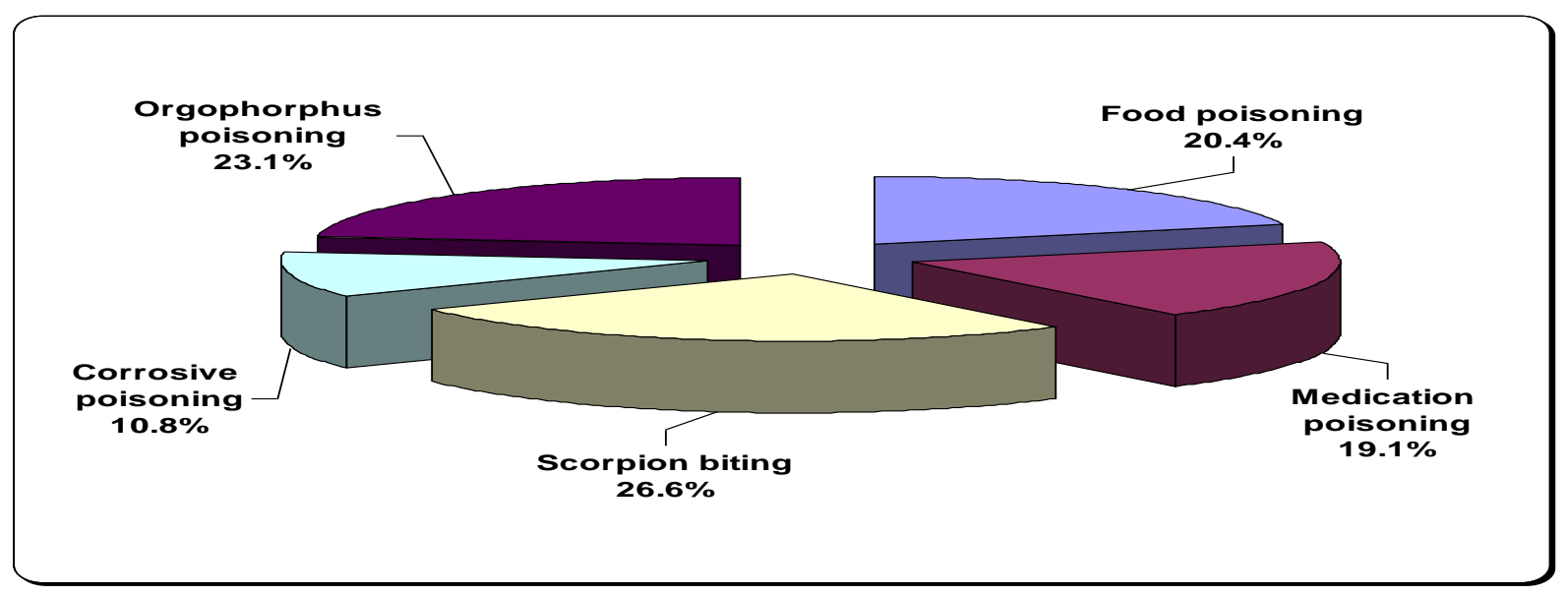


Table (1) : shows characteristics of the studied nurses. It was found that less than half of the nurses $(46.7 \%)$ their ages ranged from 24-28 years with mean age (7.19 \pm 8.77$)$. The majority of the studied nurses $(70 \%)$ had years of experience ranged from 5 10 with mean duration of 9.88 and $60 \%$ of them had in-service training courses.

Table (2) : describes the knowledge about poisoning among nurses in the study sample. It was found that no one of nurses knew complete answer of definition of poison, definition of poisoning, definition of chronic or acute poisoning.

Table (3) : describes Concerning to nurses' complete knowledge about common types of poisoning it was found that, no one of nurses knew the signs and symptoms and treatment.

Table (4) : shows nurses' practice in taking history of children suffering from poisoning. It indicates that few of nurses taking history correctly (16.7\%). In relation to obtain information related to poison it was observed that $(86.7 \%)$ of nurses didn't take any information related to poisons from the children suffering from poisoning also was found that $60 \%$ of the studied nurses didn't take anthropometric measurement of the children.

Table (5) : shows nurses' practice offered to poising children in the studied sample. As the table indicates, the highest percentages of studied nurses had adequate practice of temperature $(93.3 \%)$. On the other hand, the majority of them didn't take apical pulse, respiration or blood pressure in adequate manner (90\%, $90 \%$ and $76.7 \%$, respectively). Also, the table indicates that most of nurses $(93.3 \%)$ had an inadequate practice related to suctioning and $83.4 \%$ of them had inadequate practice of resuscitation. At the other extreme, $40 \%$ of studied nurses had adequate practice in gastric lavage.

Table (6) : Shows the relationship between nurses' knowledge and practice and their socio-demographic characteristics. It points to no statically significant association could be revealed between the nurses' knowledge and practice and any of their characteristics.

Figure (1) : This figure shows the distribution of the children according to the type of poisoning. It was noticed that scorpion biting is the most common type of poisoning occurring in $26.6 \%$ of the studied sample followed by orgophorphus poisoning $(23.1 \%)$, then food and medication poisoning (20.4\%, $19.1 \%$ respectively).

\section{Discussion:}

Childhood poisoning is a major cause of morbidity in both developing and developed countries. In spite of the success of some interventions to prevent accidental poisoning in the pediatric population, toxic ingestions continue to be a common occurrence.

The results of the current study revealed that about two thirds of nurses' age was ranging from 24-28 years and more than half of them had less than ten years experiences. Regarding training courses, it was noticed that the majority of studied sample did not attend any training courses. The present results agreed with Shehata, (2011) and Mohammed (2010) who reported that $66 \%$ and $54.6 \%$ of nurses respectively had not attend any training courses.

According to the present study findings nurses had poor knowledge about poisoning, this was indicated by their low scores (table $\mathbf{2} \mathbf{\& 3}$ ). This poor knowledge noticed among nurses' might be attributed to that, after graduation, nurses abandon reading and neglect updating their professional knowledge. Another possible reason might be the absence of any resources or programs for continued nursing education. This is in the line with, Masoud, (2006) who found that participants had poor knowledge. Also, the same finding was reached by Rutto et al., (2012) was found that nurses had poor scored in knowledge about poisoning.

The second dimension that has been explored in the present study in order to evaluate the state of nursing care offered to children with poisoning by nurses as observed through a checklist during their work. Taking history is vital part in principles of management of poisoning, findings of the present study revealed that few of nurses $(26.7 \%)$ taking history correctly such as obtain socio-demographic data, taking anthropometric measurement, This result can be attributed as the physician in this setting responsible to take history and fill the assessment record. In contrast Borowsky, (2001) who stated that the pediatric nurse must completely take history of poisoned child.

Robert, et al., (2007) emphasized that nurses must obtaining vital signs in poisoned children as a specific assessment. In this regard, the present study revealed that the majority of nurses did not verify the apical pulse, respiration and blood pressure measurements correctly. This result can be attributed as the nurses in this setting at Assuit University Children Hospital consider apical pulse, respiration and blood pressure responsibility of the physician. This result agree with Cabral, (1999) when he assessed the nurses performance of physical examination, it was found that most of studied nurses do not check children's pulse or blood pressure.

The mastery of the suctioning procedure is crucial and may be life saving in Emergency setting where the nurse might be confronted with a child with lifethreatening respiratory conditions (Masoud, 2006). The present study noticed that the majority of the 
studied nurses had inadequate performance related to suctioning. The same results were found in the study carried out by Bayoumy (1999) in Assiut.

Cardiopulmonary resuscitation (CPR) is indicated in any situation in which breathing, heartbeat, or both are absent. The nurses are generally the first responders to a cardiac arrest and initiate basic life support. When a child presents with suspected poisoning, begin with an assessment of the airway, breathing and circulation (Hwang et al., 2003). According to the present study, the majority of the studied nurses had inadequate performance related to resuscitation. The same results were found in a randomized controlled study in pediatric resuscitation carried out by Su et al., (2000) which was found poor pre training nurse's scores in resuscitation skills.

According to the present study findings, nurses practices related to gastric lavage were quite deficient. It is agree with Berkowitz, et al., (2011) who was found gap of nurses performance related to gastric lavage.

Regarding, the relation between nurses' knowledge and practice and their age, the present study could not reveal any statistically significant differences. This result agrees with Mehanny, (1999) who demonstrated no statically significant relation between the scores of nurse's knowledge or performance and their age.

On studying the relation between nurses' knowledge and their experience, the present study findings revealed that nurses with 5 - 10 years of experience had higher mean scores than those with more than 10 years of experience This might be due to nurses who have more experience will be responsible for administrative and managerial activities. This finding is congruence with Ali, (2010) and Shehata, (2011) who found that nurses performance having work experience from 5-10 years were higher than those who having work experience ranging from years, 1015 years and 15 and more.

Concerning the type of poisoning, the present study found that scorpion biting was the most common type of poisoning in the children. In trial to explain the previous result, we suggest that Assiut geographical location between Eastern and Western Egyptian deserts which are inhabited by venomous scorpion. Similarly, Amien, (2009) found that scorpion biting was the most common type of poisoning in El-Minia government. Also it is agree with Ben-Abraham et al., 2001 and Hafez, 2003 who found that the mortality rate from scorpion is usually higher because they live around houses, bites are more common.

\section{Conclusion:}

Based on the results of the present study, it was concluded that pediatric nurses in Assiut University children Hospital were lacking the necessary basic knowledge and practices related to care of children with poisoning at emergency unit.

\section{Recommendations:}

In the light of the study findings, the following recommendations are suggested.

- On Job Training (OJT) programs on regular basis is suggested in order to refresh and update nurses' knowledge, as well as reinforce proper practice related to care given to children with poisoning.

- Pediatric nurses should update their knowledge through continued nursing education, and frequently attending seminars and conferences based on their needs assessment.

- Continuous evaluation for nurses caring of children with poisoning disorders is crucial.

\section{References:}

1. Ali M.A, (2010): Assessment of nurse's knowledge and performance related to universal infection control precautions (UICP) at Mallawy general hospital departments. M.D thesis, Faculty of Nursing, Assiut University.

2. Amien N, (2009): Family awareness regarding the first aid for snake bites and scorpion stings In El-minia governorate, MD thesis Thesis, Community Health Nursing. Elmina University.

3. Barton S.J., Gaffney R., Chase T., Rayens MT.K., and Piyabanditkul L., (2003): Pediatric temperature measurement and child/ parent/nurse preference using three temperature measurement instruments. Journal of pediatric Nursing, 18 314320

4. Bayoumy S., (1999): Training Program of Nurses about respiratory infection for young children in Assiut University Hospital, MD, Thesis, HIN, Assiut University, pp: 111-19.

5. Ben Abraham R., Winkler E., Eshel G., Barzily Z., and Paret G., (2001): Snake bite poisoning in children, a call for unified clinical guide lines Eur. J. Emerg. Med., 8 (3): 189-92.

6. Borowsky I.W., (2001): "Adolescent Suicide Attempts: Risks and Protectors." Pediatrics 107: 485-93.

7. Cabral S.A., (1999): Aparelho cardiovascular. In: Rodrigues YT, Rodrigues PPB. Semiologia pediátrica. Rio de Janeiro: Guanabara-Koogan; p. 134-45.

8. Catherine E and Ardys M, (2009): Poisoning in the children, pediatric primary care, $4^{\text {th }} \mathrm{ed}$., printed in the United States, pp:1143. 
9. Elservier, (2009): Poisoning in children, text book of pediatric nursing, printed and bound at Santa printers, pp: 59.

10. Hafez M.I, (2003): Evaluation of methods of treatment of snake bite in Egypt, clinic experimental study, MD thesis, EL Minia University.

11. Hawang CF, Carole FL, Grant E, Leslie J and David RM, ( 2003): The Utility of the History and Clinical Signs of Poisoning in Childhood: A Prospective Study. Therapeutic Drug Monitoring; 25(6): 728-734.

12. Lewis-Abney k, (2000): Over dose of tricyclic antidepressants. Crit Care Nurse Oct ; 20(5):69

13. Masoud E, (2006): The impact of educational and training program on the knowledge and performance of nursing practice in the hematology and emergency unites at pediatric department of Assiut University Hospital Thesis, pediatric Nursing. Assiut University.

14. Mehanny M, (1999): The effect of a Basic Emergency Care Program on Emergency Nurses Performance. Thesis for Doctorate Degree in Medical Surgical Nursing. Assiut University.

15. Morris MC, Donoghue A and Markowitz JA, (2003): Ingestion of tea tree oil by a 4-year- old boy. Pediatr Emerg Care Jan; 19(3):169-71.

16. Mohamed A, (2001): The state of Nursing Care of Thalassemic Patients and the Design, Implementation and Evaluation of a Program to Upgrade Nursing Care for Thalassemic Patients. MSc Thesis, Pediatric Nursing. Assiut University Hospital.

17. Riordan, M., G. Rylance K and Berry, (2002): Poisoning in children: Household products, plants and mushrooms. Arch. Dis. Child., 87: 403-406.

18. Robert, H, Nelson L, How-land MA, lewin NA, Flomanbum NE, and cold-frank LR, (2007): Manual of toxicology Emergencies. $9^{\text {th }}$ ed., snakes and other reptiles, 17, (3) $933-938$.

19. Sandra AD, (2010): Poisoning among children - United States. (33):129-131.

20. Spady DW, Saunders DL and Svenson LW, (2004): Patterns of injury in children. Pediatrics Mar; 113(3):522-9.

21. Spratto GR, and Woods AL, (2008): Nurse drug handbook. $2^{\text {nd }}$ ed., Clifton Park, (71): $604-$ 1597.

22. Su E, Schmidt TA, Mann NC. And Zechnich AD, (2000): A Randomized Controlled Trial to Assess Decay in Acquired Knowledge among Paramedics Completing a Pediatric Resuscitation Course. Academic Emergency Medicine; 7(7): 779-786.
23. Weshus, N, (2004): Methods to test feeding tube placewment in children. MCN: the American Journal of Maternal/ Child Nursing,29:282-291

24. Willkinson and Richard H. (2003): complete Gods and goddesses of Ancient Egypt, Thames \& Hudson, Ltd.

25. Wong Dl, Hock Enberry-Eaton M, Wilson D, Winkelstein ML, and Schwartz P, (2001): Wong's Essentials of Pediatric Nursing. $6^{\text {th }}$ ed. St. Louis: Mosby Co.: 473-480.

26. Wong Dl, Hock Enberry-Eaton M, Wilson D, Winkelstein ML, Schwartz P, (2007):Wong's Essentials of Pediatric Nursing. $6^{\text {th }}$ ed. St. Louis: Mosby Co. P: 473-48

27. World Health Organization (WHO), 2004: Department of Violence and Injury Prevention and Disability, 20 Avenue Appia, 1211 Geneva 27 , (www.who.int/violence_injury_prevention/child/ en/). 